\title{
Investigation on the Ignition Over Pressure Related to Launch Vehicle Lift-off
}

\author{
R. Venkatraman 1*, S. Sankaran', S. V. Subba Rao', P. Krishnaiah² and T. Sundararajan ${ }^{3}$ \\ 'Scientist, Satish Dhawan Space Centre, Sriharikota, India-524124; rvraman@shar.gov.in, \\ sankaran.s@shar.gov.in,svsrao@shar.gov.in \\ 2Professor, Sri Venkateswara Univeristy, Tirupathi, India \\ 3Professor \& Head, Department of Mechanical Engineering, IIT Madras; tsundar@iitm.ac.in
}

\begin{abstract}
Several transient events occur during the startup of the Solid Rocket Motor (SRM) during the launch vehicle lift-off. Each event produces a complex transient signal and requires systematic assessment. The event discussed in this paper is Ignition Over Pressure (IOP). This Ignition Over Pressure is resulting from fluid dynamic compression of the accelerating plume gas, subsequent rarefaction and propagation during the pressure rise rate period in the rocket combustion chamber. These high-amplitude unsteady fluid-dynamic perturbations can adversely affect the vehicle and its surrounding structure. This wave behaves as a blast or shock wave characterized by a positive triangular shaped first pulse and negative half sine wave second pulse.

The pulse travels upwards towards the propulsion system and has the potential to overload the individual elements or exciting overall vehicle dynamics. The later effect results from the phase difference of the wave from one side of the vehicle to the other due to the skew in the ignition of the strap-on boosters.

In the case of the launchers, the mechanical stress due to the ignition over pressure wave comes, in addition to the acoustic constraint due to the jet noise. The over pressure phasing or $\Delta \mathrm{P}$ environment, because of its spectral content as well as amplitudes becomes a crucial input for the design of sub-assemblies viz., thermal shields, and pay loads etc. In this paper, an attempt is made to numerically visualize the propagation of the blast wave causing the unsteady pressure oscillations during the transient pressure rise in the combustion chamber. To understand further, pressure measurements have been made at different heights along the umbilical tower during the solid rocket motor lift-off with the presence of jet deflectors, in order to capture the shock propagation phenomena. From the results, it appears that a sudden shock front that is generated during flow development within the rocket nozzle leaves a clear signature in the form of a well defined peak at typical time intervals. This overpressure amplitude seems to be related to the slope of the combustion chamber pressure rise rate during the transient period. It is also observed that the shock front initially propagates at supersonic speed but decays with time later. Similarly, the magnitude of the IOP peaks are also seen to decay with distance.
\end{abstract}

Keywords: Ignition Over Pressure, Shock Wave Propagation, Ignition Transient, Solid Rocket Motor, Numerical Flow Visualization.

\section{Introduction}

During the start-up process of a solid rocket motor, transient pressure waves are generated in the combustion chamber. These pressure waves propagate outward and interact with the launch vehicle and its surroundings, resulting in spatial and time dependent pressure disturbances. The pressure disturbance $(\Delta \mathrm{P})$ is defined as,

$$
\Delta \mathrm{P}(\mathrm{x}, \mathrm{y}, \mathrm{z}, \mathrm{t})=\mathrm{P}(\mathrm{x}, \mathrm{y}, \mathrm{z}, \mathrm{t})-\mathrm{P} \propto
$$

where, $\mathrm{P}(\mathrm{x}, \mathrm{y}, \mathrm{z}, \mathrm{t})$ is the transient pressure at any location $(\mathrm{x}, \mathrm{y}, \mathrm{z})$ and time $(\mathrm{t})$, and $\mathrm{P} \propto$ is the atmospheric pressure.

*Corresponding author:

R. Venkatraman (rvraman@shar.gov.in) 
This pressure disturbance which originates from the rocket ignition process is termed as the Ignition Over Pressure (IOP). A typical IOP signal measured during the launch of NASA's STS-1 motor is shown in Figure 1. It is evident that the pressure fluctuation of IOP corresponds to a low frequency large amplitude pulse. The frequency may typically lie in the range of $20-50 \mathrm{~Hz}$. In the present work, it is aimed at to throw some light on the reason for the occurrence of IOP with the help of experiments and detailed numerical simulation of the ignition transient flow from the rocket motor.

Depending upon the maximum over pressure, the disturbance wave may induce unsteady pressure fluctuations at low frequencies on the vehicle structure and more significantly injure the payloads in the encapsulated assembly of the launch vehicle. Determination of the maximum IOP is also necessary in order to protect the payload area and launch vehicle structure and its vicinity.

\section{Literature Review}

The first analytical model for ignition overpressure has been devised by Broadwell and Tsu ${ }^{1}$ using one dimensional linear wave theory. It requires two empirical constants; one accounts for combustion in the exhaust gases and the other for momentum loss. NASA observed a very low frequency (approx. $5 \mathrm{~Hz}$ ) ignition overpressure wave during the lift-off of Space Transportation System-1 (STS-1). The magnitude of ignition overpressure wave has been suppressed with water injection during the (STS-2) Space Transportation System-2. ${ }^{2}$

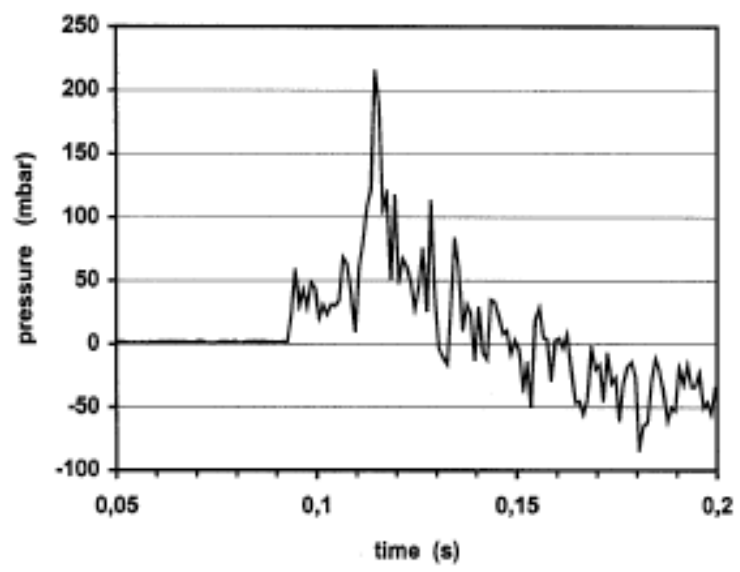

Figure 1. Typical IOP signal from the transient of solid rocket motor.
Lai and Laspesa ${ }^{3}$ conducted experiments for full scale and sub-scale models. It has been observed that full scale models have been characterized by low frequency overpressure waves whereas subscale models have been characterized by high frequency pressure oscillations. Canabal and Frendi ${ }^{4}$ developed an inviscid flow model for Silo and Minuteman launchers using the finite element method. Their numerical results agree well with experimental data. Canabal and Frendi ${ }^{5}$ studied the ignition overpressure suppression using water injection. The study demonstrated that ignition overpressure is strongly affected by the cooling of the plume and the extent of obstruction which restricts the expansion of the plume. Various computational techniques were employed by many researchers to predict the ignition over-pressure in different launch vehicle environments. Computational one-dimensional and two-dimensional axis-symmetric studies were carried out for Minuteman and Titan silo launchers by Francisco Canabal et al. ${ }^{4,5,11,12}$ they have used a numerical technique to solve the nonlinear Euler equation in their study, which is described as a combination of a temporal discretization scheme, a spatial discretization scheme and a discontinuity capturing scheme. Good agreement was obtained by them with test data for the Minuteman and Titan silo launchers. Francisco Canabal et $\mathrm{al}^{4,5,11,12}$ have also studied the interactions between the ignition overpressure generated by launch vehicles and water injection distribution to the engine plume. Varnier et al have carried out number of experiments to understand the IOP signatures during the static testing of typical solid rocket motors. ${ }^{6,7}$ They have done rocket motor testing

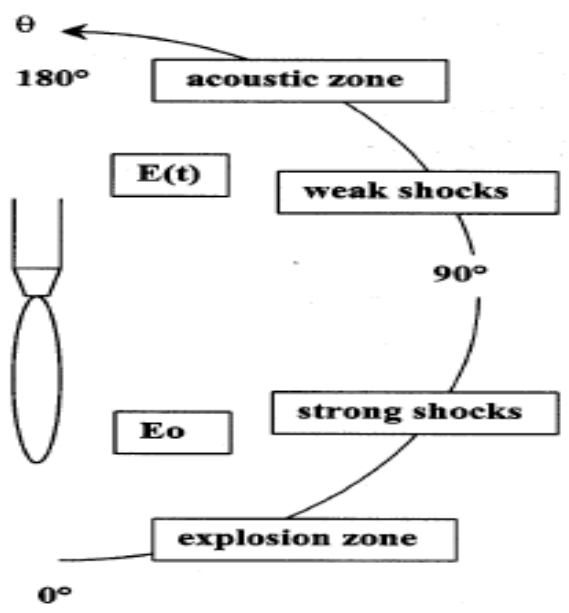

Figure 2. IOP wave directivity ${ }^{6}$. 
with out and with solid grain and igniter configuration to understand the directivity of IOP propagation, amplitude and the effect of chamber pressure rise rate on the IOP characteristics. Marshall et al. have developed a semi-empirical method for predicting the peak surgeinduced overpressures in the vicinity of the engine face, as a function of engine cycle variables. ${ }^{8}$ Ikawa et al. have developed an analytical methodology that offers some physical understanding of the IOP mechanism. ${ }^{9}$ They have developed two models, one mathematical model for IOP prediction and another analytical model for the Duct Over Pressure (DOP) predictions and has used $6.4 \%$ sub-scale model test results of solid rocket motors for validations.

Walsh et al. have worked to develop a good correlation flight measured lift-off ignition over pressure and suppression with sub-scale model tests. ${ }^{10}$ They have found that subscale data exhibited a higher attenuation level than the flight data even though the waveforms were qualitatively comparable in both the subscale and flight data. Another new attenuation model is presented by Simon et al for computing and correlating ignition overpressure attenuation, as it propagates upward from its source using Titan III flight data and $7.5 \%$ scale model data. ${ }^{13}$ Through this new attenuation model, they have identified that both the attenuation and the overpressure source location are same for both model and flight. Colombier et al. has presented a method to predict the ignition overpressure of solid rocket motors using a fluid dynamics code namely FLUSEPA and CEL3B. ${ }^{14}$ Troclet et al. have localized the sources from one of the typical ARIANE 5 flight measurements to rebuild the unsteady pressure field so as to estimate the pressure levels at any point of the vehicle for other flights. ${ }^{15}$ By integrating the unsteady pressures over all surfaces of the launchers, the loads created by overpressure were estimated in his work. They have concluded that the sources model seems to be a good and robust predictive tool for computation of acoustic environment on the launcher, during overpressure phase of many ARIANE flights. Troyes et al. have focused on the effects of nozzle shape, motor pressure build-up rates and post-combustion of motor exhaust plume with ambient air using two-dimensional axi-symmetric flow description. ${ }^{16}$ Buell et al. by assuming inviscid, compressible and one component flow, have developed three-dimensional model of the shuttle, launch mount, and solid rocket booster (SRB) duct in order to predict the characteristics of the pressure wave that travels down the SRB ducts, past the duct exits, and back to the vehicle. ${ }^{17}$ They have used their newly developed code COMPIN3 to integrate the three-dimensional Euler equations and has obtained a scaling factor, which was useful in analyzing the subscale test data. Julien Troyes et al..$^{18}$ through their work have established the detailed reactive large eddy simulation (LES) computations, in order to understand major phenomena that contribute to the overpressure waves generated during solid rocket booster ignition on the launch pad. Their work have comparisons with detailed measurements of the generated overpressure waves and has thrown valuable insight of the major mechanisms responsible for the production of intense pressure waves which are of concern when designing the launch pad mitigation devices.

In the present study, an attempt has been made to experimentally understand the propagation of IOP wave, which is causing unsteady pressure oscillations and transient pressure rise in the stagnation chamber of typical solid rocket motor. Also preliminary studies have been carried out to numerically visualize the propagation of the blast wave causing the unsteady pressure oscillations during the transient pressure rise in the combustion chamber. To understand further, pressure measurements have been made at different heights along the umbilical tower during the solid rocket motor lift-off with the presence of jet deflectors, in order to capture the shock propagation phenomena. From the results, it appears that a sudden shock front that is generated during flow development within the rocket nozzle leaves a clear signature in the form of a well defined peak at typical time intervals. This overpressure amplitude seems to be related to the slope of the combustion chamber pressure rise rate during the transient period. It is also observed that the shock front initially propagates at supersonic speed but decays with time later. Similarly, the magnitudes of the IOP peaks are also seen to decay with distance.

\section{Ignition Over Pressure (IOP) Measurement on the Umbilical Tower During a Typical Launch Vehicle Lift-off with Solid Boosters}

The following experiments were exclusively designed to capture the IOP signature during the launching of typical propulsion system with solid rocket as boosters from 
the launch pad. During the ignition transient of the solid rocket motor and lift-off, IOP waves are generated and these are expected to propagate spherically all round the launch pad. Hence, it has been decided to measure these IOP signatures along the Umbilical Tower (UT) from where, the launch vehicle is designated to lift-off. By positioning the suitable IOP sensors along the height of the umbilical tower as shown in Figure 3, IOP signatures could be captured and with time data, the propagation characteristics could be understood. As shown in Figure 3, at various elevations of $7 \mathrm{~m}$ to $72 \mathrm{~m}$, Druck \& Kulite type piezo resistive pressure sensors of 0.18 " size with 5 psi and 15 psi ranges were used to measure the IOP signals at 10 locations with equal intervals. These measurements would give a better insight on the IOP wave propagation characteristics with respect to distance and time. During the ignition transient of the solid rocket motor and liftoff, IOP waves are generated and these are expected to propagate spherically. During this period, each sensor from S1 to S10 kept at $7 \mathrm{~m}$ and $72 \mathrm{~m}$ respectively would record a pressure peak at different time intervals.

Figure 4 gives the time history plots at various elevations from $7 \mathrm{~m}$ to $72 \mathrm{~ms}$ at 10 different locations. The time at which the pressure peaks recorded at $7 \mathrm{~m}$ to $72 \mathrm{~m}$ along the umbilical tower height are $330,360,370,380,400$, $420,440,450,460 \& 500$ milli seconds respectively. These values are plotted in Figure 5 and best fit is drawn. From this best fit line, the slope has been computed to derive the average velocity $(\mathrm{ds} / \mathrm{dt})$. The shock wave travels at an average velocity of about $413 \mathrm{~m} / \mathrm{s}$ (Mach Number $=1.25)$, which is at supersonic speed. However, it is to be noted that the actual propagation characteristics are non-linear. The decay of the peak pressure amplitude with time and distance is also plotted in Figure 6. The peak pressure recorded at $7 \mathrm{~m}$ height along the umbilical tower is 38.3 milli bar at a time interval of $t=330 \mathrm{~ms}$, whereas, at $72 \mathrm{~m}$ height, the peak pressure recorded is 4.6 milli bar at a time interval of $\mathrm{t}=500 \mathrm{~ms}$. Initially, the decay rate is found to be higher for $\mathrm{t}=330 \mathrm{~ms}$ to $370 \mathrm{~ms}$. The decay is found to be very gradual for $\mathrm{t}=440 \mathrm{~ms}$ to $500 \mathrm{~ms}$.

\section{Numerical Flow Visualization Studies}

Numerical simulations have been carried out for a full size motor similar to the launch vehicle booster using

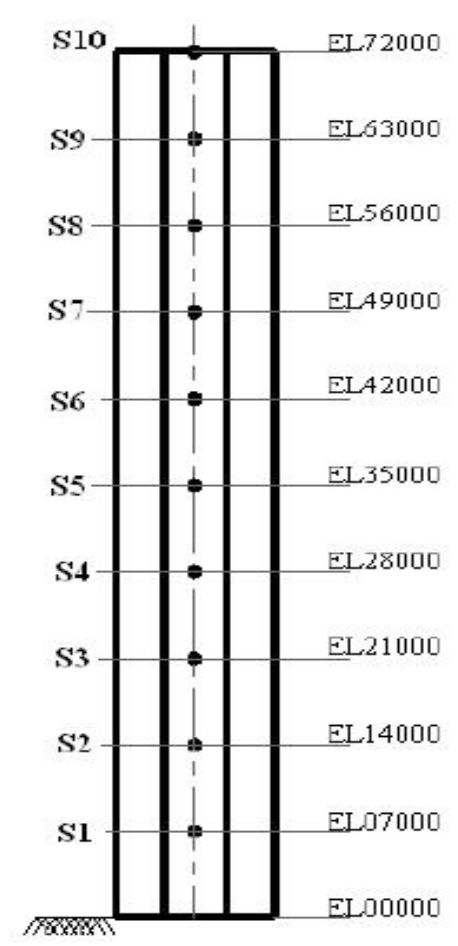

ELEVAT ION OF UMBLICAL TOWER(FRONT FACE)

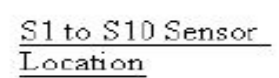
Location

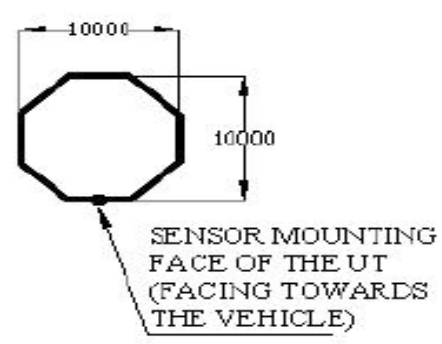

PLAN VIEW OF

UMBLICAL TOWER

TYPICAL)

$\underline{\text { A11 Dimensions are in } \mathrm{mm}}$

Figure 3. Location of IOP measurement along the umbilical tower at various heights. 

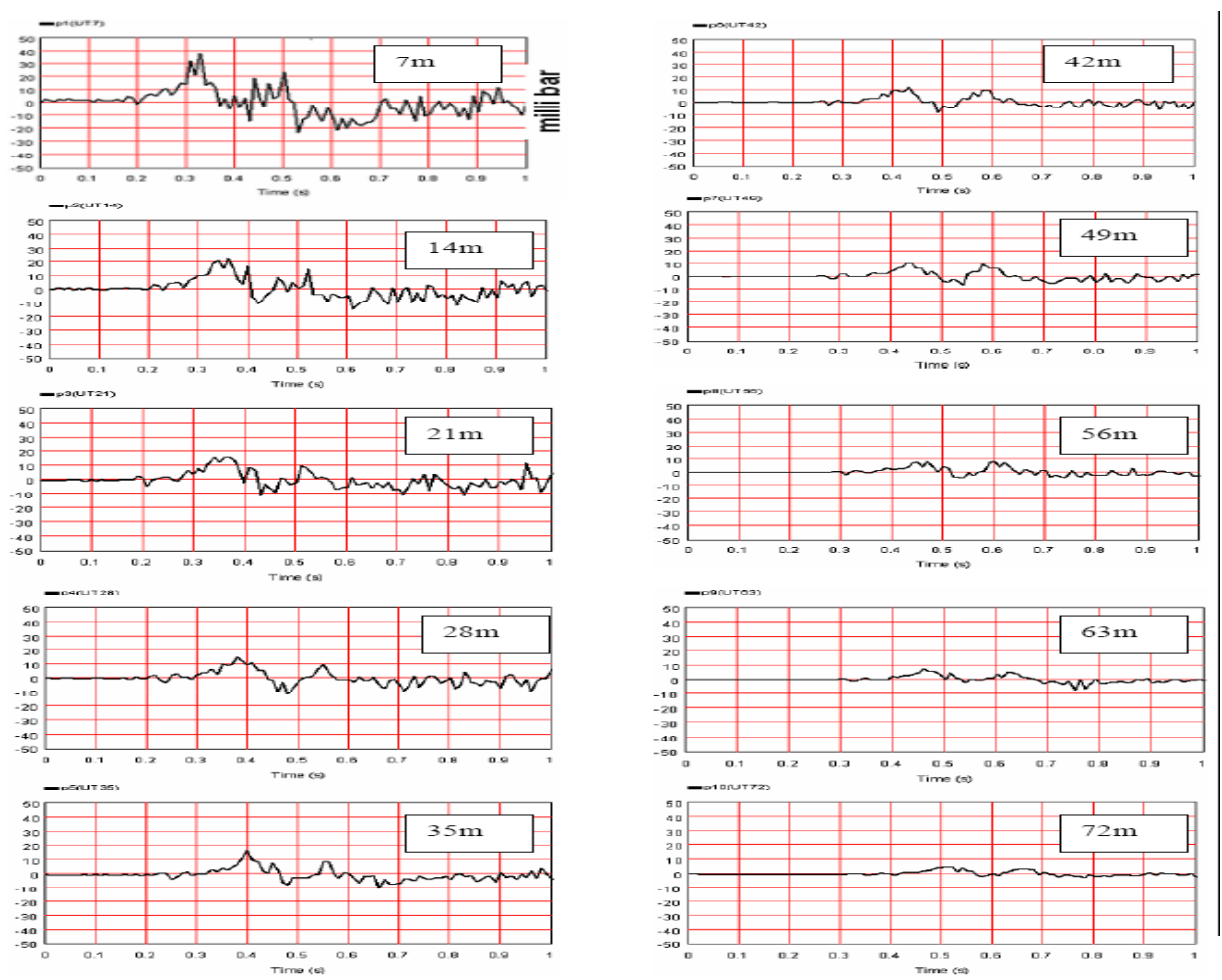

Figure 4. Ignition Over Pressure (IOP) wave propagation characteristics along the umbilical tower height during the launch vehicle lift-off.

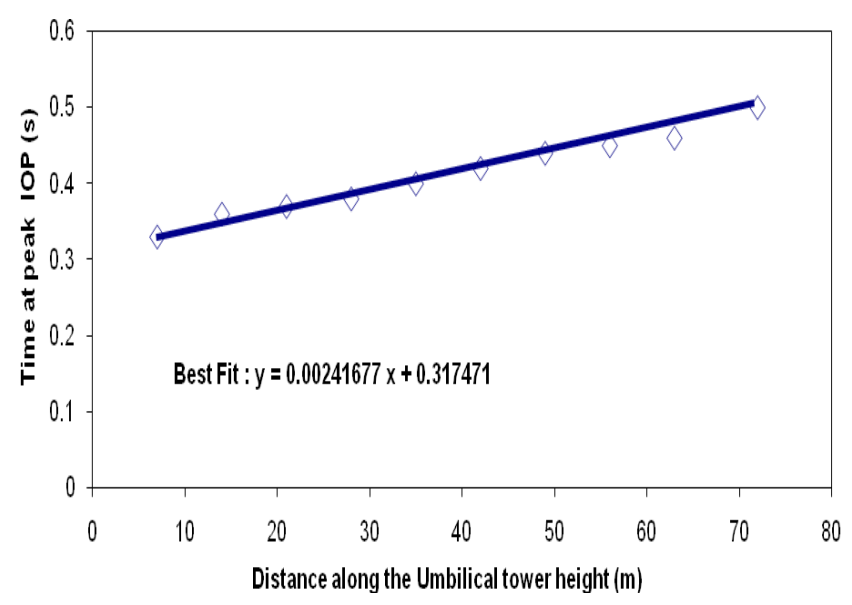

Figure 5. Ignition Over Pressure (IOP) wave propagation characteristics.

the commercial CFD software tool at TDCE Laboratory, IIT Madras. The spalart-Allmaras turbulence model has been adopted in the turbulent compressible flow simulation. The steady state mass flow rate of the motor is $1950 \mathrm{~kg} / \mathrm{s}$. The exhaust flow from the motor has been simulated for three different stand-off distances 3De, 4.5De, and $6 \mathrm{De}$, where $\mathrm{De}$ is the motor nozzle exit

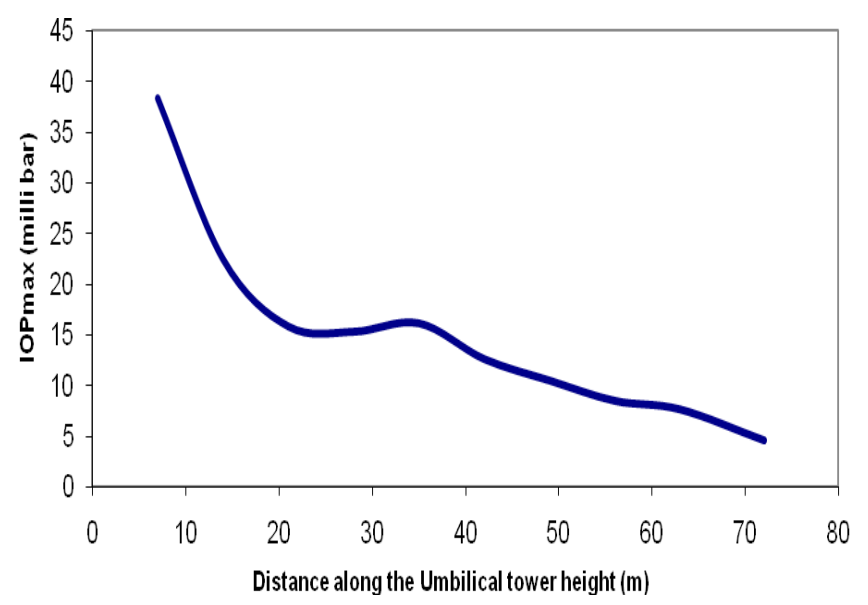

Figure 6. Decay of Ignition Over Pressure (IOP) magnitude with time.

diameter. The computation has been carried out for three ignition times of $50 \mathrm{~ms}, 100 \mathrm{~ms}$ and $150 \mathrm{~ms}$, the computational domain with boundary condition is shown in Figure 7. The entire domain was discretized in to $200 \mathrm{~K}$ structured cells of uniform size. Numerical solution is obtained by advancing with respect to time, in steps of $0.3 \mathrm{~ms}$ time increments. 


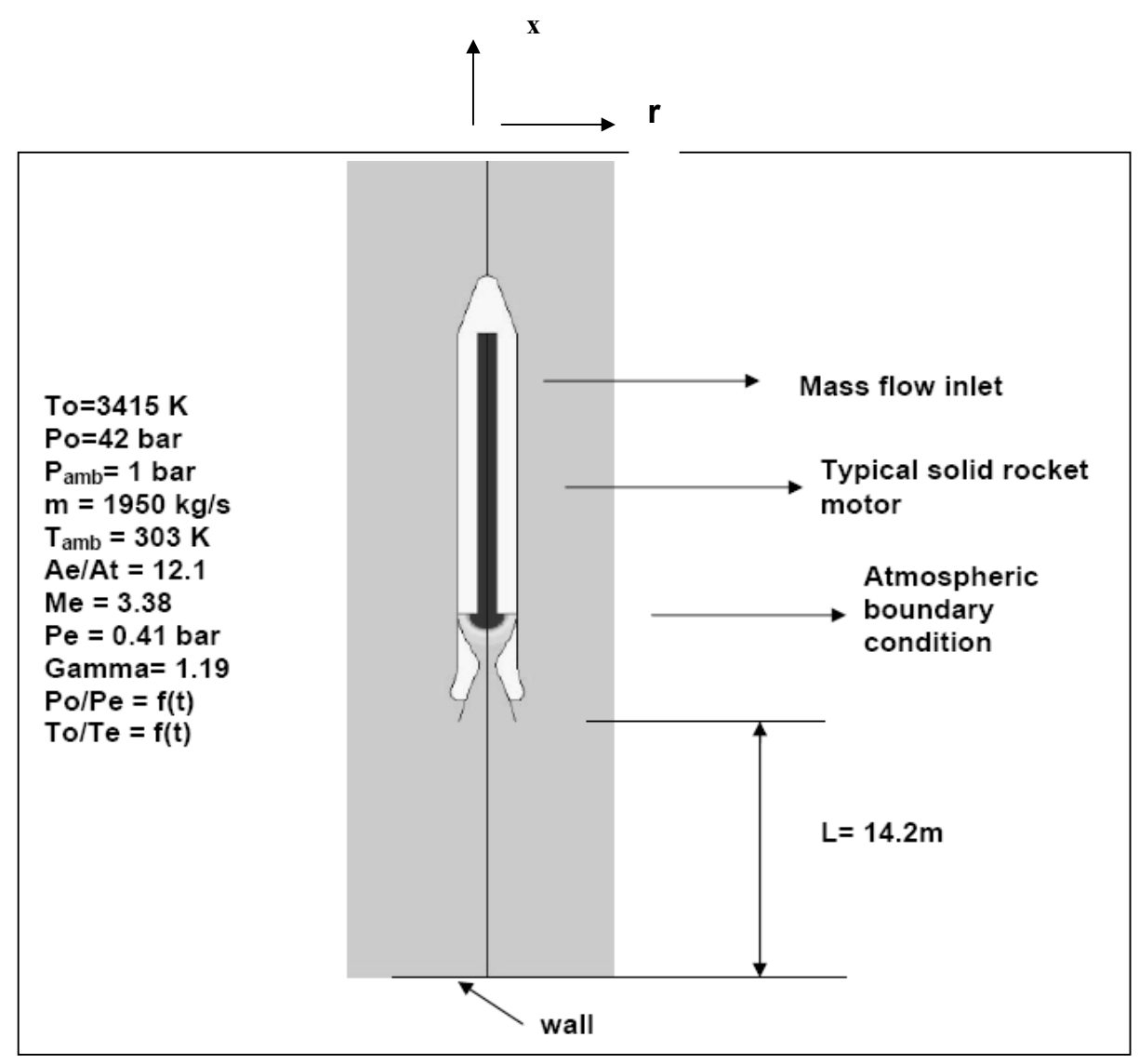

Figure 7. Typical geometry \& general boundary conditions employed.

Numerical simulations have been carried out for full size without nozzle shutter. The simulation begins with stagnant air filled inside the combustion chamber, nozzle and surroundings of the vehicle at time $t=0$. For time $t>0$, the combustion chamber pressure continues to increase due to hot gas inflow until it reaches steady state value.

\subsection{Governing Equations}

The unsteady governing equations in axi-symmetric form for simulating the jet flow are discussed below. The flow field is characterized by the viscous, compressible NavierStokes equations.

For axi-symmetric geometry, the mass balance equation is of the form

$$
\frac{\partial \rho}{\partial t}+\frac{\partial\left(\rho u_{x}\right)}{\partial x}+\frac{\partial\left(\rho u_{r}\right)}{\partial r}+\frac{\rho u_{r}}{r}=0
$$

where, $x$ is the axial coordinate, $r$ is the radial coordinate, $u_{x}$ is the axial velocity, and $u_{r}$ is the radial velocity.
The axial and radial momentum conservation equations are given by

$$
\begin{gathered}
\quad \frac{\partial}{\partial t}\left(\rho u_{x}\right)+\frac{\partial}{\partial x}\left(\rho u_{x} u_{x}\right)+\frac{1}{r} \frac{\partial}{\partial r}\left(r \rho u_{r} u_{x}\right) \\
=-\frac{\partial p}{\partial x}+\frac{\partial}{\partial x}\left[\mu\left(2 \frac{\partial u_{x}}{\partial x}-\frac{2}{3}(\nabla \cdot \vec{u})\right)\right] \\
+\frac{1}{r} \frac{\partial}{\partial r}\left[r \mu\left(\frac{\partial u_{x}}{\partial r}+\frac{\partial u_{r}}{\partial x}\right)\right] \\
\frac{\partial}{\partial t}\left(\rho u_{r}\right)+\frac{\partial}{\partial x}\left(\rho u_{x} u_{r}\right)+\frac{1}{r} \frac{\partial}{\partial r}\left(r \rho u_{r} u_{r}\right) \\
=-\frac{\partial p}{\partial r}+\frac{\partial}{\partial x}\left[\mu\left(\frac{\partial u_{r}}{\partial x}+\frac{\partial u_{x}}{\partial r}\right)\right]+\frac{1}{r} \frac{\partial}{\partial r} \\
{\left[r \mu\left(2 \frac{\partial u_{r}}{\partial r}-\frac{2}{3}(\nabla \cdot \vec{u})\right)\right]-2 \mu \frac{u_{r}}{r^{2}}+\frac{2}{3} \frac{\mu}{r}(\nabla \cdot \vec{u})}
\end{gathered}
$$

where, $p$ is the static pressure and $\rho$ is the density. Also, $\nabla \cdot \vec{u}=\frac{\partial u_{x}}{\partial x}+\frac{\partial u_{r}}{\partial r}+\frac{u_{r}}{r}$ 
The energy equation for compressible viscous flow is given as

$$
\frac{\partial}{\partial t}(\rho e)+\nabla \cdot(\vec{u}(\rho E+p))=\nabla \cdot\left(k_{e f f} \nabla T-\sum_{j} h_{j} \vec{J}_{j}+\left(\overline{\bar{\tau}}_{e f f} \cdot \vec{u}\right)\right)
$$

In the above equation $k_{\text {eff }}$ is the effective conductivity ( $k_{\text {eff }}=k+k_{t}$ where $k_{t}$ is the turbulent thermal conductivity and $k$ is the laminar thermal conductivity) and $\vec{J}_{j}$ is the diffusion flux of species $j$. Also the three terms on the right-hand side represent energy transfer due to conduction, species diffusion, and viscous dissipation, respectively. Also the specific total energy $e$ is defined as

$$
e=h-\frac{p}{\rho}+\frac{u_{x}^{2}+u_{r}^{2}}{2}
$$

\subsection{Boundary Conditions}

The boundary conditions employed (Figure 3) for jet flow simulations are as listed below.

\subsubsection{Mass Flow Inlet}

The mass flux of the exhaust gas is represented by

$$
\text { Mass flux }=\frac{m^{\bullet}}{\mathrm{A}} \times t
$$

It has been assumed here that the mass flow rate of the exhaust gas increases linearly with time during the ignition period.

\subsubsection{Far Field Boundary Condition}

Atmospheric pressure and temperature boundary condition with zero second gradients are prescribed.

$$
P=P_{\infty}, \frac{\partial^{2} u_{x}}{\partial x^{2}} \rightarrow 0, \frac{\partial^{2} u_{r}}{\partial r^{2}} \rightarrow 0, T \rightarrow T_{\infty}
$$

\subsubsection{Axi-symmetric Boundary Condition}

A zero normal gradient is applied for the flow variables on the axis of symmetry

$$
u_{r}=0, \frac{\partial T}{\partial r}=0, \frac{\partial u_{x}}{\partial x}=0, \frac{\partial u_{r}}{\partial r}=0
$$

\subsubsection{Wall Surface}

No slip condition for the velocity components is imposed on the "rigid flat plate" (simulating flat ground) on which the jet is impinging. Due to the short time of contact, this surface is also assumed as adiabatic. Hence,

$$
u_{x}=0, u_{r}=0, \frac{\partial T}{\partial n}=0
$$

\subsection{Spalart-Allmaras Turbulence Model}

In turbulence models that employ the Boussinesq approach, the central issue is how the eddy viscosity is computed. The model proposed by Spalart and Allmaras solves a transport equation for a quantity that is a modified form of the turbulent kinematic viscosity. The transported variable in the Spalart-Allmaras model, is identical to the turbulent kinematic viscosity except in the near wall region.

$$
\begin{aligned}
& \frac{\partial}{\partial t}(\rho \bar{v})+\frac{\partial}{\partial x_{i}}\left(\rho \bar{v} u_{i}\right)=G_{v}+\frac{1}{\sigma \bar{v}} \\
& {\left[\frac{\partial}{\partial x_{j}}\left\{(\mu+\rho \bar{v}) \frac{\partial \bar{v}}{\partial x_{j}}\right\}+C_{b 2 \rho}\left(\frac{\partial \bar{v}}{\partial x_{j}}\right)^{2}\right]-Y_{v}+S_{\bar{v}}}
\end{aligned}
$$

where, $G$ is the production of turbulent viscosity and $Y$ is the destruction of turbulent viscosity that occurs in the near-wall region due to wall blocking and viscous damping.

\subsection{Numerical Flow Visualization on the IOP Wave Propagation}

The results presented here are pertinent to the ignition overpressure (IOP) generated by representative launch vehicle including launch pad configuration. The motor size, vehicle dimensions and solid motor start-up transient characteristics are based on the typical launch vehicle first stage booster. The launch pad considered here consists only of a simple rigid plate over which the jet exhaust plume is expected to impinge on. This configuration, though idealized, could be described as representative of future advanced propulsion systems with solid rocket as boosters. The investigation proceeds through a series of numerical solutions in order to obtain the flow field involved. The computational domain includes the motor chamber, nozzle as well as the motor and vehicle surroundings. The entire domain, including 
the motor, vehicle, and its surroundings were discretized and arranged in an unstructured mesh (figure not shown). The higher concentration of elements within the motor and near the nozzle exit provides the required resolution for the proper numerical prediction of the flow field. The appropriate element size distribution is achieved through gird independency studies.

Figure 8 shows the sequence of pressure distributions at various time intervals from $\mathrm{t}=3 \mathrm{~ms}$ to $\mathrm{t}=165 \mathrm{~ms}$. In this series of figures, the time increases from top to bottom, column wise. The range of pressure contours has been narrowed to the interval from $9 \times 10^{4} \mathrm{Pascal}$ to $1.11 \times 10^{4}$ Pascal. From the figures, for $\mathrm{t}=3 \mathrm{~ms}$ to $14 \mathrm{~ms}$, the pressure rise in the chamber is not appreciable. For $\mathrm{t}=18 \mathrm{~ms}$ to $\mathrm{t}=30 \mathrm{~ms}$, a spherical disturbance wave begins to form and spread outwards. Though at this condition, the chamber pressure is not sufficient enough to make the nozzle flow full and hence flow separation takes place in the nozzle divergent. At $\mathrm{t}=45 \mathrm{~ms}$, the nozzle is just running full with a lip shock present. The initial spherical wave is moving towards the vehicle nose cone causing significant pressure fluctuations. This phenomenon is confirmed during the actual flight measurement of IOP briefed in the subsequent section. The effect of the presence of a solid wall below the nozzle is very significant, which is observed from Figure 8 for time intervals beyond $t=53 \mathrm{~ms}$. The jet exhaust impinges on the flat plate and propagates radially outwards. The resultant shock wave gets reflected due to the presence of the solid wall and moves upwards towards the vehicle nose cone resulting in a very complex flow field structure, which is evident from the Figure 8 for $\mathrm{t}=58 \mathrm{~ms}$ to $\mathrm{t}=165 \mathrm{~ms}$.

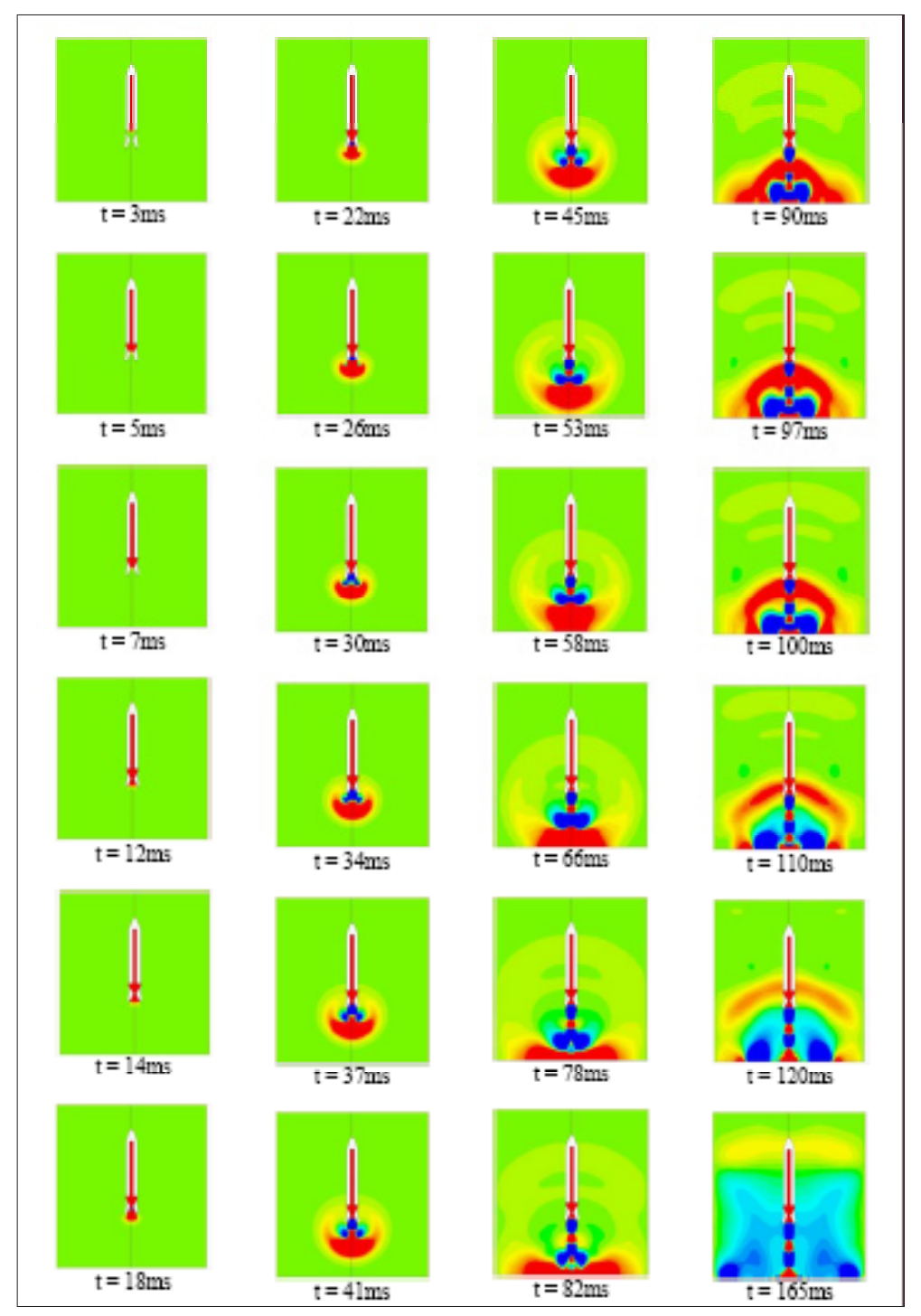

Figure 8. Ignition Over Pressure (IOP) propagation characteristics with time. 


\section{Conclusion}

A preliminary attempt has been made to examine the Ignition Over Pressure (IOP) generated by a typical solid propellant rocket motor during transient period. Computational fluid dynamics principles have been used to numerically visualize the flow field for a given solid motor configuration with the presence of a rigid flat plate underneath. Experiments were also carried out to understand this phenomenon by measuring IOP at various locations along the umbilical tower during the launch vehicle lift-off having solid motors as boosters. Results indicate that a sudden shock front is generated due to the blast wave, has left clear signatures in the form of well-defined peaks at typical time intervals during the transient period. It is also observed that the shock front initially propagates at supersonic speed and later decays with time. Similarly, the magnitude of the IOP peaks is also seen to decay with distance. Hence, further tests at certain scales simulating the launch conditions appear to be necessary to obtain best similarities and to improve the understanding of the complex mechanisms related to the Ignition Over Pressure wave during the start up of the solid rocket motors.

\section{References}

1. Broadwell JE, Tsu CN. Transient pressures caused by rocket start and shutdown in ducted launchers. J Spacecraft Rockets. 1967; 4(10):1323-1328.

2. Dougherty NS, Nesman TE, Guest SH. Shuttle SRB ignition over pressure: model suppression test program and flight results. JANNAF $13^{\text {th }}$ Plume Technology Meeting. Houston, Texas, USA: CPIA Publication; 1982. p. 217-243.

3. Lai S, Laspesa FS. Ignition over pressure measured on STS lift-off and correlation with subscale model tests. JANNAF $13^{\text {th }}$ Plume Technology Meeting. Houston, Texas, USA: CPIA Publication; 1982. p. 207-216.

4. Canabal F, Frendi A. A computational study of the ignition over pressure for launch vehicles. $8^{\text {th }}$ AIAA/CEAS Aeroacoustic Conference and Exhibit. Brekenridge, Colorado, USA; 2002. Report No: AIAA 2002-2541.

5. Canabal F, Frendi A. Suppression of ignition over pressure generated by launch vehicles. $10^{\text {th }}$ AIAA/CEAS Aeroacoustic Conference. Manchester, United Kingdom; 2004. Report No: AIAA 2004-2833.
6. Varnier J. Blast wave at ignition of the rocket engines. ISMA 2002, Louvain (Belgique), TP 2002-175; Ce document comporte 9 pages, Ce Tiré à part fait référence au Document d'Accompagnement de Publication DSNA0224, Onde de souffle à l'allumage des propulseurs par; 2002.

7. Varnier J. Experimental study of the blast wave at ignition of rocket engines. $6^{\text {th }}$ International Symposium on Launchers Technologies, MUNICH; 2005. ALLEMAGNE Ce Tiré à part fait référence au Document d'Accompagnement de Publication DSNA0543.

8. Marshall FL. Prediction of inlet duct overpressures resulting from engine surge. J Aircraft. 1973; 10(5):274-278.

9. Ikawa H, Laspesa FS. Ignition/duct overpressure induced by space shuttle solid rocket motor ignition. J Spacecraft Rockets. 1985 Jul-Aug; 22(4):481-488.

10. Walsh EJ, Hart PM. Flight-measured lift-off-ignition overpressure-a correlation with subscale model tests. J Spacecraft Rockets. 19(6).

11. Canabal F, Frendi A. Study of the ignition overpressure suppression technique by water addition. J Spacecraft Rockets. 2006 Jul-Aug; 43(4):853-865.

12. Canabal F, Frendi A. On the suppression of ignition overpressure generated by launch vehicles. $9^{\text {th }}$ AIAA/CEAS Aeroacoustics Conference and Exhibit; 2003 May; Hilton Head South Carolina.

13. Simon ED. Titan III ignition overpressure attenuation. AIAA/SAE/ASME 19 ${ }^{\text {th }}$ Joint Propulsion Conference; 1983 Jun; Seattle Washington.

14. Colombier R, Pollet M. Solid rocket motor ignition overpressure prediction. 27 $7^{\text {th }}$ Joint Propulsion Conference; 1991 Jun; Sacramento CA.

15. Troclet B, Jeanjean S, Alestra S, Terrasse I, Identification of overpressure sources at launch vehicle lift-off using an inverse method. AIAA Modeling and Simulation Technologies Conference and Exhibit; 2003 Aug; Austin Texas.

16. Troyes J, Vuillot F. Numerical simulations of model solid rocket motor ignition overpressure waves. $44^{\text {th }}$ AIAA/ ASME/SAE/ASEE Joint Propulsion Conference \& Exhibit; 2008 Jul; Hartford CT.

17. Buell JC. Three-dimensional simulation of sts ignition overpressure. AlAA $17^{\text {th }}$ Fluid Dynamics, Plasma Dynamics and Lasers Conference; 1984 Jun; Snowmass, Colorado.

18. Troyes J, Vuillot F, Varnier J, Malbequi P. Numerical simulations of rocket solid motor engine ignition and duct overpressure waves at reduced scale. $45^{\text {th }}$ AIAA/ASME/ SAE/ASEE Joint Propulsion Conference \& Exhibit; 2009 Aug; Denver, Colorado. 